Resumo

\title{
Perfil da resiliência no contexto esportivo: um estudo com as equipes de alto rendimento do Exército
}

Marcos Paulo Sena da Silva Bsci, Ângela Nogueira Neves PhD

Introdução: Atletas são um grupo que necessitam de elevada resiliência para superar obstáculos e lograr êxito em suas performances.

Objetivo: A presente pesquisa analisou traços da resiliência nos atletas militares de alto rendimento.

Métodos: Participaram do estudo 56 atletas militares (28,71 $\pm 5,64$ anos). Cada atleta, respondeu as escalas: Fator de Satisfação com a vida da Escala de BemEstar Subjetivo; Inventário de Lócus de controle para praticantes de atividade física; Brief Resilience Scale e Questionário demográfico. Foram utilizados os testes $\mathrm{t}$ de Student e One Way ANOVA para o tratamento estatístico das amostras.

Resultados: 0 escore médio da escala de resiliência foi $3,74( \pm 0,52)$ pontos, estatisticamente distinto de amostras de pesquisa anterior. 0 mesmo teve uma correlação significante com a escala de satisfação com a vida, mas não com os tipos de lócus de controle. 0 teste $\mathrm{T}$ de Student revelou não haver diferenças estatisticamente significantes em relação ao escore da escala de resiliência entre os sexos. De igual forma, o teste One Way ANOVA indicou não haver diferenças no escore de resiliência em relação ao tipo de modalidade. Também não foi observada qualquer diferença estatisticamente significante em relação à percepção do desempenho esportivo atual e os escores de resiliência.

Conclusão: A resiliência tem uma relação positiva com nível de satisfação com a vida. 0 escore da escala de resiliência parece não depender do sexo do atleta, da modalidade praticada nem da percepção do desempenho esportivo atual.

Palavras-chave: aperfeiçoamento esportivo; lócus de controle; performance desportiva; potencial de resiliência; satisfação com a vida; saúde mental. 